\title{
Bebês na arte vivida em casa: experimentando e (re) criando o cotidiano em tempos de pandemia
}

Karla Jeniffer Rodrigues de Mendonça ${ }^{1}$

Ailza de Freitas Oliveira ${ }^{2}$

Submetido em: 17/08/2020

Aprovado em: 30/10/2020

DOI: 10.5965/23580925242020053

1 Mestra e Doutoranda em Sociologia pela Universidade Federal da Paraíba (UFPB). Professora da Prefeitura Municipal de João Pessoa. E-mail: karla-pessoa@hotmail. com

2 Doutora em Educação (UFPB). Professora efetiva de Educação Básica II na Prefeitura Municipal de João Pessoa,no Ensino de Artes Cênicas. E-mail: ailzafreitas@ hotmail.com 


\section{RESUMO}

Este artigo objetiva analisar as experiências artísticas de bebês e suas mães durante o isolamento social causado pela pandemia de COVID-19. O método realizado foi a pesquisa qualitativa com a aplicação de questionários semiestruturados respondidos por seis mães de bebês entre cinco meses e três anos de vida, via aplicativo de mensagem no celular, acompanhado de produção de vídeos, fotografias e relatos de experiências. Observamos que a vivência com a arte pelos bebês com suas mães se dá como lazer e atividades educacionais no que o ambiente oferece, a partir dos hábitos dos adultos e na experimentação das novidades. Nisso, com os/ as bebês refletimos que ao vivenciar as possíveis formas artísticas, o cotidiano de casa se (re) faz com suas presenças transformadoras e ações curiosas no processo sensitivo de desenvolver suas habilidades criativas. Neste estudo, percebemos que é no que já se dispõe em casa que as crianças pequenas mais entram em contanto com as artes, isso se revelou nas rotinas domésticas com suas mães e nas práticas inseridas nesses cotidianos para alegrar, educar e aprender junto.

Palavras-chave: bebês, arte, mães, pandemia

\section{ABSTRACT}

This article aims to analyze the artistic experiences of babies and their mothers during the social isolation caused by the pandemic of COVID-19. The method carried out was a qualitative research with the application of semi-structured questionnaires answered by six mothers of babies between five months and three years of age, via a mobile message application, accompanied by the production of videos, photographs, reports of experiences. We observed that the experience with art by babies with their mothers occurs as leisure and educational activities in what the environment offers, based on the 
habits of adults and in the experimentation of novelties. In this, with the babies we reflect that when experiencing the possible artistic forms, the daily life of the home is (re) done with their transforming presences and curious actions in the sensitive process of developing their creative skills. In this study, we realized that it is in what is already available at home that small children come into contact with the arts the most, this was revealed in the domestic routines with their mothers and in the practices inserted in these daily lives to cheer, educate and learn together.

Keywords: babies, art, mothers, pandemic.

\section{PRIMEIRAS PALAVRAS}

Este artigo trata do cotidiano de bebês em tempos de pandemia de COVID-19 e suas experiências com/nas linguagens artísticas com seus familiares. Apresenta e reflete as vivências e as produções dos/das bebês ${ }^{3}$ de 5 meses a 3 anos reconhecidas, nas relações intergeracionais de seus lares, como ações criativas no contato com a arte. Nesse processo, procuramos (re) pensar de modo interdisciplinar, entre os campos dos estudos sociais da infância e da arte na infância, o contexto doméstico como dinâmico e de relativo isolamento, já que os bebês se relacionam não só com os sujeitos humanos, mas também com os não-humanos (LATOUR, 2005).

No confinamento de seus lares, geralmente aos cuidados das mães, o cotidiano dos bebês e das crianças pequenas nesse

3 Categorizamos bebês a partir do entendimento das mães em relação ao modo de como reconhecem seus filhos e filhas, também coparticipantes dessa pesquisa ao se fazerem presentes nos relatos de suas ações através de suas mães. Também tomamos como referência tais categorias não só em relação aos estágios na primeira infância e as habilidades sociais, verbais e motoras, mas considerando as subjetividades sociais reconhecidas nas relações socias do contexto vivido pelas famílias. Por vezes nos referimos aos bebês como crianças pequenas (GOLTTLIEB, 2009). 
trabalho aparece nos espaços e tempos (re)definidos por suas cuidadoras de acordo com as rotinas domésticas, seus trabaIhos em home-office e as atenções às suas necessidades. Considerando os modos como acontece o isolamento social dessas famílias, procuramos entender como e se as linguagens artísticas chegam à essas casas situadas em contextos urbanos de algumas capitais do Brasil. O caminho foi percorrido a partir dos relatos de mães sobre a relação com suas crianças, explorando quais atividades são entendidas por elas como vivências e produções artísticas de seus/suas bebês. Acrescentamos que não é o foco deste trabalho analisar se as mães vivenciam ou não as linguagens artísticas com seus/suas bebês, não procuramos avaliar seus conhecimentos a respeito do assunto, mas visamos entender com essas mulheres as possíveis práticas que a arte se faz presente em casa na vida de seus filhos e filhas.

A conversa foi realizada através de aplicativo de mensagens via celular com 6 mães conhecidas de ambas as pesquisadoras, através do qual foram compartilhadas conversas não-formais, entrevistas com perguntas pré-formuladas, fotos e vídeos. Os relatos das participantes emergidos nesse contato estão presentes no decorrer do texto e identificados por M.1 a M.6. Os nomes dos seus filhos e filhas estão identificados por letras abreviadas, respeitando o sigilo de suas identidades.

Cinco das mães colaboradoras dessa pesquisa residem em casa com quintal, enquanto que uma delas em apartamento de três capitais brasileiras (Curitiba- PR, João Pessoa- PB e Manaus - AM). Em relação à formação acadêmica, cinco possuem curso superior nas áreas da música (M. 1), artes plásticas (M. 2), administração (M. 3), ciências sociais (M. 4) e filosofia (M. 5), e uma delas estudou até o ensino médio (M. 6). Dentre elas, M. 1 e M. 2 possuem dois filhos, sendo um deles bebê, enquanto M. 4 seus dois filhos são bebês. M. 3 e M. 5 ambas possuem um bebê e M 6. três filhos, sendo um deles bebê. Em relação às suas realidades ocupacionais durante a pandemia, três delas estão dividindo o trabalho doméstico com seus trabalhos profissionais formais em home office, duas delas estavam desempregadas em relação às suas formações, realizando trabalhos em suas residências para angariar renda, para além dos salários de seus 
companheiros, sendo que uma delas recebe auxílio emergencial; outra mãe já tinha uma rotina em casa, antes da pandemia, por não possuir trabalho formal e recebe bolsa família; e uma mãe sai para trabalhar enquanto o companheiro cuida da filha.

Ao considerarmos trazer o diálogo entre as crianças pequenas e a arte, objetivamos compreender como as múltiplas linguagens artísticas são pensadas pelas famílias no ambiente doméstico, valorizando como emerge esse envolvimento das crianças a partir/com/ no corpo na relação com o ambiente oferecido, sentido e experienciado. Apresentamos as ações infantis nas relações com as mães e as coisas (INGOLD, 2012) dando destaque às suas experiências como fonte de possível aprendizagem, imaginação e criação. É nessa dinâmica que vislumbramos perceber como as crianças pequenas se relacionam com os gêneros artísticos e os direciona atenção, experimentam e se empenham em produzir novos feitos, atentando a como (re) criam o espaço-tempo de suas casas com suas curiosidades.

Para isso, dividimos esse artigo em três partes: primeiramente apresentamos a concepção de infâncias e bebês considerada neste trabalho, refletindo as crianças como produtoras de cultura e dotadas de agência (PIRES; SARAIVA, 2019) no tecido social em que participa, procurando, desse modo, desconstruir o entendimento adultocêntrico de que a infância está submetida apenas aos investimentos do adulto para sua aprendizagem e experimentação do mundo. Em seguida abordamos o conceito de arte relacionando-o às vivências na infância, tendo a arte como experiência social humana, que acompanha as trajetórias de vida desde o nascimento. No tópico seguinte refletimos como as linguagens artísticas são compreendidas e vividas no espaço-tempo do confinamento social com as crianças pequenas a partir do relato de suas experiências por suas mães. Por fim, concluímos que é no se fazer presente com as pessoas e as coisas (INGOLD, 2012) no território que ocupam em seus lares cotidianamente, que os/as bebês sentem e (re) criam criativamente o que/quem está disposto à eles, no experimentar das linguagens artísticas, nas alteridades de seu crescimento e no desenvolvimento de suas habilidades no/com/a partir do corpo. 


\section{OS BEBÊS E AS INFÂNCIAS}

A primeira infância informalmente é conhecida como fase ou período inicial de vida das crianças. A partir dos conceitos nascidos da psicologia do desenvolvimento, os primeiros anos de vida das crianças é identificado por processos de maturação e transformação do corpo, necessitando, assim, de cuidados essenciais relacionados ao seu desenvolvimento evolutivo dentro do que se considera saudável em relação às etapas de seu crescimento. Nessa compreensão, o entendimento dos bebês enquanto sujeitos ocorre no campo da vulnerabilidade e da passividade, tratando seu crescimento e desenvolvimento a partir do vir a ser pelas competências em construção, valorizando-se desse modo instituições, ações e avaliações em relação a suas habilidades motoras, sociais e linguísticas.

A primeira infância, assim entendida, ou seja, a partir da perspectiva da psicologia do desenvolvimento, entre a bifurcação de conceitos biológicos e culturais a respeito de quando/ como ela começa e termina, além de suas características existenciais, padroniza esse período em estágios e fases cronologicamente determinados (GOLTTLIEB, 2009). Tal conhecimento, historicamente induz ao que hoje entendemos de como/quem são os bebês. Essa problemática em revelar como se vive a primeira infância em contextos sociais diversos, demonstra o quanto "estudar bebês é colocar a linguagem, a epistemologia e as metodologias em tensão, já que os sentidos não estão dados a priori" (TEBET; ABRAMOWICZ, 2018, p. 941).

Ao tratarmos do assunto de uma perspectiva socioantropológica, a presença dos bebês continua sendo um campo em construção e revela, na multiplicidade das infâncias (ABRAMOWICZ et al, 2009), a importância de produções sobre os modos de viver a primeira infância em diferentes contextos e práticas sociais. Nessa construção parece que o principal desafio aos pesquisadores é a comunicação, pois os bebês exigem a modificação do olhar, do ouvir e do perceber como participam no mundo. Alma Golttlieb (2009) aponta reflexões sobre os modos 
de comunicação não centrados especificamente na fala, mas no corpo como "afirmações somáticas do bebê" (GOLTTLIEB, 2009, p. 325), isto é, como e com quem, ou com o que os bebês se relacionam demonstram como "os corpos dos bebês são marcos significativos que apontam valores culturais críticos" (idem).

Ao entendermos as infâncias enquanto categoria geracional em trajetória de vida, considerando sua complexidade e variabilidade de acordo com as práticas culturais enredadas nas relações intra e intergeracionais, podemos entender nosso processo de vida considerando os seres viventes enquanto agentes biopsicossociais, autopoiético e históricos (INGOLD, 2001; TOREN, 2012), isto é, somos fruto de uma história em que nossas ações, sensações, condições físicas e ambientais desde o nascimento, e até antes dele, estão dinamicamente se enredando. Por isso, "do mesmo modo que não há uma imagem produzida sobre a criança, também não há sobre o bebê que não seja contextual, fruto de processos históricos" (SALUTTO; NASCIMENTO, 2019, p. 25). Por isso, concordamos que:

Se até mesmo os bebês modelam ativamente a vida das pessoas à sua volta, contribuindo para a constituição de seus mundos sociais, certamente deve haver uma lição para nós, como analistas que buscam a compreensão da vida social em geral (GOLTTLIEB, 2009, P. 327).

Ao compreendermos os bebês como sujeitos potentes nas práticas culturais, não negamos a sua dependência dos adultos em relação aos seus cuidados e bem-estar diante de seus direitos fundamentais. O que procuramos valorizar é como na relação intergeracional, as especificidades dos bebês fluem e podem ser visibilizadas enquanto compreensão e (re) produção de cultura, especificamente nas linguagens consideradas artísticas em seus lares ao serem acompanhados e cuidados por suas mães. 


\section{A PRODUÇÃO ARTÍSTICAS NAS INFÂNCIAS}

Produzir artisticamente é uma necessidade nata da humanidade. Encontramos registros artísticos oriundos de todas as civilizações, desde os mais remotos tempos, povos distintos se manifestaram por intermédio da arte, registrando características de suas culturas, histórias e expressando seus sentimentos. De forma voluntária ou intuitiva, obrigatória ou utilitária, decorativa ou essencial, a arte acompanha a humanidade em seus mais variados fazeres.

Ao pensarmos a vivência das artes e as crianças, são as com mais idade, com maior autonomia na locomoção e na fala que aparecem nos trabalhos relacionados com o tema, já que colaboram com uma maior interação no processo planejado pelos adultos, nos papéis de educador/professor e alunas (OLIVEIRA, 2016; KAISER, 2017). As artes na infância, aparecem nesses estudos como instrumento pedagógico de vivências lúdicas, estimuladoras de habilidades, visando a conquista de capacidades projetadas de acordo com as idades em que as crianças se encontram.

Na educação infantil, quando presente, se reconhece nessas práticas modalidades de cuidado e educação, procurando oferecer aos bebês a partir/com essas linguagens processos criativos e ativos com o corpo, possibilitando assim conectar e florescer sentidos e emoções no vivido (INFANTINO; ZUCCOLI, 2015; OLIVEIRA, 2016). As ações de observar, experimentar, tocar, sacudir, imitar, assim como os jogos de faz de conta e as brincadeiras utilizando-se de brinquedos ou apenas dos recursos corporais, são experiências associadas à primeira infância enquanto processos criativos, refletindo sobre como revelam seu processo de improvisação, de curiosidade imaginativa e inventiva. São seus primeiros passos relacionados à estética, ao ritmo, com o jogo dramático, à atenção às linhas, às texturas e ao diálogo com a criação. 
criança estão os livros, a música, as pinturas, o cinema, a dança, além da criança explorar e conhecer o que se está colocando na brincadeira, se pode dizer que se está contribuindo para o nascimento da sensibilidade estética. [...] A arte, como os jogos, é a ruptura com o habitual, com o sabido. A percepção estética modifica a pessoa que percebe. $O$ fato de que a arte seja um lugar de experiência, significa que as crianças e os adultos aprendem algo sobre si mesmos e sobre o mundo, além de estremecer-se ou divertir-se, e que do encontro com a arte ninguém volta sem algum lucro emocional, estético, subjetivo e também cognoscitivo (LÓPEZ, 2013, p.23-25).

Assim é que para os bebês "o conhecimento das linguagens artísticas acontece primeiro no corpo" (CUNHA, 2018, p. 12), é no toque e no contato com os sentidos, em especial o paladar, que inicia a sua relação com o mundo. Na variabilidade de suas vivências e territórios que participam os bebês, desenvolvem suas atenções e apegos, como retrata Winniccott (1982 [1964], p.190), é um mundo real que tem muito a oferecer, desde que "a sua aceitação não signifique uma perda da realidade do mundo pessoal imaginativo ou interior. Para a criança pequena é legítimo que o mundo interior tanto esteja fora como dentro".

Antes de adentrar ao universo da educação formal, iniciado nas primeiras séries de ensino na educação infantil, podemos reconhecer que o contato e a produção artística dos bebês já ocorrem no âmbito intergeracional familiar. Chanan (2016, p. 14), defende que "depois que a criança nasce, o processo de formação da inteligência acontece a partir do contato com seu entorno", numa construção oriunda da interação com o meio, as pessoas e os objetos. Assim, consideramos que a produção artística inicia e se desenvolve numa (re) construção relacional. Tocando, criando, inventando, mudando e ousando, os bebês produzem, em suas brincadeiras e experimentações, ações criativas participando e movimentando o contexto que ocupam.

Cunha (2018, p. 06) afirma que "dentre as paixões que as crianças demonstram pelo mundo e seus mistérios, estão aquelas que decorrem das descobertas relativas à arte e seus procedimentos de feitura". O brincar, como atividade prazerosa, fala 
aos sentidos e aguça os novos e criativos saberes, é um processo imaginativo e sensível de descobertas em que a criança pequena vive uma mistura de ações no imitar, repetir e reinventar, principalmente na ociosidade possível dos tempos de suas brincadeiras, pois "ao brincar, a criança transforma a materialidade do mundo através do corpo e das linguagens formando imagens e a sua imaginação criadora" (PAASCHEN, 2012, p. 04). Isso não significa que se faz necessária a presença de objetos artísticos convencionais e técnicas previamente estipuladas, mas, proporcionar a possibilidade para que o bebê crie e desenvolva processos criativos com liberdade expressiva, fazendo uso (ou não) de objetos artísticos do cotidiano, mas sempre explorando o seu potencial infinito de criação.

Reconhecemos que "o que há de mais valor nessas vivências são as interações estabelecidas e as formas criativas de explorar, mais do que um objetivo a seguir, pois o processo deve ser o próprio objetivo" (CHANAN, 2016, p. 16), assim como no modo de produção artística entre os artistas adultos na mistura da imaginação criativa e da intuição que marcam o tempo e espaço no experimentar e sentir no/o mundo através de suas produções. A criação artística tem sua importância na ação processual, enquanto elemento próprio de desenvolvimento humano de contato e experimento com a arte, vista como meio e não como fim. Observar o fazer arte dando importância ao processo é uma forma de valorizar as descobertas das crianças.

\section{OS BEBÊS, AS MÃES E AS ARTES}

É comum encontrarmos a participação dos bebês em trabalhos acadêmicos, mesmo enquanto coadjuvantes, com temáticas relacionadas ao cuidado e à educação. Estão geralmente acompanhados por mulheres, suas mães, avós e educadoras, isto é, suas cuidadoras. São a partir delas e com elas que as crianças pequenas foram geralmente visibilizadas, principalmente em alguns trabalhos com linhas de pensamentos feministas ao tratarem da vida privada das mulheres (ALANEN, 2001).

Nesses cotidianos, planejados ou não, é que a adultez aca- 
ba por se reinventar o que, certamente, exige uma vulnerabilidade das adultas, isto é, das mães como as principais cuidadoras presentes nos contextos da vida dos bebês no ambiente doméstico urbano. Seja pela intenção de divertir ou de educar, a presença de práticas e experiências entendidas como artísticas com os bebês, as mães se apresentam como sensíveis a um processo relacional de aprendizagem que acontece entre ambos os envolvidos.

Laisy Nunes, Fabíola Aquino e Pompéia Villachan-Lyra (2015) ao investigarem como 20 mães de bebês de 4 meses e 20 mães de bebês de 9 meses entendem a respeito das habilidades socioemocionais dos seus bebês, analisaram que "o modo como as mães veem e compreendem as habilidades socioemocionais e comunicativas infantis norteiam seus comportamentos e cuidados nas interações com os bebês". Nessa pesquisa em que uma das participantes afirma: "mãe acha que bebê sente tudo, né?", revela um discurso que aponta a perspectiva relacional de como as emoções de tristeza, alegria, medo e surpresa, das mães e dos bebês, se (re) constroem e se alimentam em um contrato sensível. Do mesmo modo, as autoras também apontam que as mães ao atribuírem:

[...] significados aos comportamentos das crianças, as mães revelam parte das suas percepções sobre o desenvolvimento infantil e sobre aspectos específicos desse desenvolvimento, tais como as habilidades socioemocionais infantis (NUNES; AQUINO; VILLANCHAN, 2015, p. 244).

Nesse sentido, ao procurarmos analisar como os bebês vivenciam as linguagens artísticas em casa, em tempos de pandemia, devemos reconhecer que as mães participantes dessa pesquisa, possuem um repertório de capital cultural para que essas vivências sejam reconhecidas e praticadas. Como enfatiza Lahire (1997):

Dado que o "capital cultural" está condenado, de um lado, a viver em estado incorporado, sua "transmissão" ou sua "herança" dependem da situação de seus portadores: de sua relação com 
o filho, de sua capacidade, (socialmente constituída) de cuidar de sua educação, de sua presença a seu lado, ou, finalmente, de sua disponibilidade de transmitir à criança certas disposições culturais ou acompanhá-la na construção dessas disposições (LAHIRE, 1997, p. 105, grifos do autor).

Como dito no texto introdutório, tivemos contato com seis mães de bebês de 5 meses à 3 anos, as quais se dispuseram a responder algumas perguntas direcionadas e participaram de rápidas conversas informais por meio de aplicativo de Whatsapp via celular. Atentamos que neste formato de pesquisa não presencial, pouco utilizada ou ausente nas pesquisas com bebês, ressalta exclusivamente os discursos e entendimentos das mães sobre seus e suas bebês, uma vez que remotamente não podemos associar outros instrumentos de coleta de dados como a observação, por exemplo. Nesse âmbito, respeitamos os limites do compartilhamento das informações através do canal de comunicação escolhido, ao qual todas têm acesso, e o tempo disponível e cedido por essas mulheres na atenção com as pesquisadoras. Vale salientar que nas atribulações e funções que essas mães desempenham em seus cotidianos, quatro delas responderam de modo escrito e por áudio às perguntas direcionadas no aplicativo, enviaram, inclusive, vídeos e fotos, enquanto duas delas optaram por escrever e enviar um texto único.

De acordo com quatro das participantes desta pesquisa a concepção de arte aparece enquanto práticas educacionais e de lazer, pois "é excelente para aguçar os sentidos com brincadeiras sensoriais e de texturas. Um bom estímulo visual e motor, além de instigar a criatividade" (M. 4, relato via WhatsApp, junho de 2020). No entanto, três das mães ao serem indagadas a respeito dessas experiências com seus/suas bebês, reconheceram não direcionar vivências nesse sentido, mas que se vive a arte em casa com as crianças nas práticas já vividas pelos adultos e no que a criança passa a se interessar ao oferecerem ou buscarem materiais no improviso do cotidiano.

$\mathrm{O}$ acesso a programas musicais infantis no netflix e youtube em sua maioria, independente da condição social, é a forma de 
arte que entendem ter maior atenção de seus pequenos, além de "encantá-los" enquanto realizam suas tarefas como cozinhar e limpar a casa. Dentre as famílias, duas indicaram que apesar de entenderem os atrativos desses programas, tentam evitá-los proporcionando experiências mais práticas com suas crianças. Percebemos que a partir desses musicais, dos quais Mundo de Bita está entre os mais citados, segundo as genitoras, os bebês se envolvem pelos sons e movimentos com o olhar e balançar de seus membros, o que empolga a família.

A mãe M. 3 conta que os programas que a sua bebê tem acesso, pela televisão e pelo celular, são Daniel Tigre (Netflix) e Maria Clara e JP (Youtube). O primeiro programa refere-se à um desenho animado educativo, que explora sons e cores para transmitir significados às crianças e o segundo são vídeos produzidos em um canal no Youtube por duas crianças com sua mãe, que ao inventarem histórias utilizando-se de jogos de imagem desconstroem o ambiente em que convivem e recriam histórias com personagens favoritos. Ambos são programas entendidos como "infantis" e a criança passa considerável tempo os assistindo. A mãe conta também que a criança aprecia dançar ao som de músicas que os adultos da casa escutam e relata imitar a intérprete de libras das lives que a família assiste.

Observamos que a vivência com as músicas e vídeos musicais que as famílias escutam acabam fazendo parte do repertório também da criança e é assim que os estilos de viver ao acompanhar seus pais, "no mundo adulto", são reconhecidos e apropriados pelas crianças à medida que vivem o confinamento, observando os movimentos e informações através das telas. No entanto, esses materiais, fazendo parte da vida diária das adultas, se tornam parte dos objetos disponíveis aos bebês que, desse modo, viram foco de suas atenções e desejos de saber suas funções e possíveis diversões. De fato, concordamos que o uso desses equipamentos pelas crianças pequenas quando substituem a atenção dos seus e suas cuidadoras em suas atividades de interesse, na intenção de ocupá-los hipnoticamente, pode acarretar transtornos em seu desenvolvimento social, cognitivo e emocional, como aponta a OMS (Organização Mundial 
da Saúde) $)^{4}$.

A disposição de experimentar materiais e atividades aprendidas em fontes compartilhadas na internet, por aplicativos sociais, também aparece nas famílias que têm mais de uma criança em casa, como fontes de sugestões para desenvolverem atividades artísticas, como por exemplo: fazer espuma colorida e massinha para explorar formas e cores. Nesses aplicativos, como o Instagram, inúmeros são os perfis que trabalham com ideias para explorar essas atividades durante a quarentena 5 .

Notou-se a aquisição de brinquedos artesanais de madeira, jogos de montar e outros materiais que sejam aproveitados por suas crianças criativamente em quatro das famílias entrevistadas, relatando o investimento em materiais manipulativos coloridos para seus bebês explorarem, os quais se tornam ferramentas artísticas segundo elas. Ao entrarem em contato com lápis e canetinhas quando as mães oferecem, começam a aparecer pela casa as formas dos primeiros rabiscos realizados pelos bebês, principalmente quando procuram esses materiais ao verem os adultos e os irmãos manuseando. Em poucas das famílias entrevistadas, aparece a criação de materiais com os bebês por parte das mães ou de outro cuidador. Em uma delas, destacamos a criação de um móbile e de dobraduras como experimentação da arte, incentivado como prática de interesse do irmão mais velho.

Além das linguagens gráficas de seus rabiscos e formas em processo de descoberta, a procura pelo alcance de materiais como livros, parece ser uma forma de arte que as mães entendem como significativa nessa etapa da vida. Nas casas em que as mães têm formação de nível superior, os livros destinados

4 Sobre isso ver reportagem: OMS divulga recomendações sobre uso de aparelhos eletrônicos por crianças de até 5 anos. Publicado em 26/04/2019. Atualizado em 02/05/2019. Disponível em: https://nacoesunidas.org/oms-divulga-recomendacoes-sobre-uso-de-aparelhos-eletronicos-por-criancas-de-ate-5-anos/

5 Em uma pesquisa rápida encontramos os seguintes perfis que sugerem atividades utilizando as artes com as crianças pequenas: @infanvia.viva.viva; @ arte_infancia; @arte.e.infancia; @arteinfancia; @alice_infancia @afroinfancia; @ territorio_do_brincar, entre outros. 
aos pequenos de literatura infantil, que os acompanham até no banho, são elementos que agregam na descoberta e na compreensão de cores e imagens, as quais são relacionadas com a fala de suas mães ao apontarem seus nomes.

De acordo com as mães que possuem habilidades musicais e instrumentos, os bebês despertam o interesse em manipulá-los logo cedo, principalmente aqueles destinados aos adultos, experimentando-os não necessariamente como os adultos de casa, mas também procurando imitar os movimentos ou descobrindo sons a partir do que produzem na ação com seus corpos. De acordo com três mães, caso não estivéssemos atravessando esse período de isolamento por conta da pandemia, seus bebês estariam participando de aulas de musicalização para bebês, nas quais um deles já participava desde os 8 meses de vida. Segundo os relatos, a música e os instrumentos vividos em casa, desperta e prende a atenção dos bebês de modo criativo, ações que acabam fazendo parte do cotidiano:

L. sempre fica batendo na porta do quarto do J. enquanto ele estuda piano, e, assim que termina, L. pede para tocar, explora livremente, e já sabe ligar umas músicas gravadas no teclado, chamando a gente pra dançar. (M. 2, relato via WhatsApp, junho de 2020).

Em um vídeo compartilhado por M.1, seu bebê se interessa por um pandeiro da mãe no qual a mãe relata que ele já entende que ao bater o som é emitido. Em seguida explora com cuidado as platinelas entendo a diferença do som que ouviu anteriormente, girando com as mãozinhas habilidosas. Diz que seu bebê aprecia muito a música, em especial quando o pai toca instrumentos de percussão e trompete, comentando que isso acontece desde muito cedo, por volta dos 8 meses de vida. Segundo ela:

Desde menor ele é louco pelas minhas baquetas e já sabe a finalidade delas, pois ele já procura algo que possa bater. Outro dia, organizado as miçangas em potes eu fiz um pouco de batuque. Na sequência ele pegou e fez a mesma coisa. Ele já pegava a lata 
de leite e colocava de cabeça para baixo e batia nela [...] outro dia achei uma versão da música fazendinha no Youtube onde aparecia os músicos tocando, e ele ficou parado assistindo bem atento (M. 1, Relato via WhatsApp, junho de 2020).

Observamos que objetos que os lares já dispunham no cotidiano vão despertando o interesse das crianças pequenas ao perceberem os pais utilizando cotidianamente. Na atenção ao que está disponível, pela imitação e pela imaginação (re)criam novas experiências. Em uma das famílias, registrou-se o inusitado em ver seus filhos fazendo o que chamaram de "pintura com água" na parede, que, segundo a criança com mais idade, o bebê percebeu as formas impressas na parede que as gotas de água faziam e convidou o irmão para experimentar, o que rendeu fotos para mostrar à família que mora em outro estado. Os relatos relacionados às pinturas na parede e, na extensão, pelo próprio corpo com canetinhas, tintas e da terra que algumas das famílias dispõe em seus quintais, revelam espaços que as crianças pequenas e os bebês procuram ocupar, remoldando a estrutura estética do lugar. 


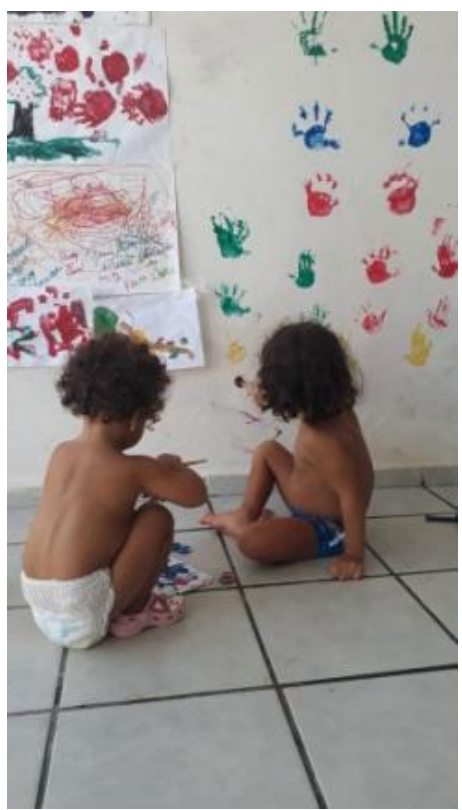

Figura 01: Parede.

Fonte: foto registrada por M. 4 (whatsapp, 26/06/2020)

Arquivo da autora

É interessante perceber, que as famílias em sua maioria e dependendo da estrutura física de suas moradias, se preocupam em deixar o ambiente seguro para as possíveis aventuras de seus/suas bebês. No entanto, em duas famílias, isso não sendo possível, as crianças se ocupam com objetos da casa que transmitem sons e cores, como tecidos, panelas e potes utilitários, fazendo desses dois últimos tambores. A comida também aparece como instrumento criativo para seus/suas bebês ao olharem com cuidado as formas e a união das cores em seus pratos, os quais pintam telas de colorida textura no chão ou em suas cadeirinhas de alimentação.

O faz-de-conta também foi relatado como presente na 
ação criativa das crianças pequenas, transformando redes em cabanas, blocos de montar em companheiros nas danças e nas brincadeiras de cozinhar. Perceber como se "fica bonita" ao se olhar no espelho e imitar as ações vaidosas da mãe, manipulando suas bijuterias, retrata as iniciais percepções de estética das crianças pequenas. Parece que as "coisas dos adultos" são divertidas referências para os bebês e para as crianças pequenas descobrirem e sentirem o movimento do mundo de modo criativo. É como uma das mães aponta:

\begin{abstract}
A arte é tão importante quanto comida e abrigo. É preciso para a construção de um ser sensível e inteiro. Além da construção do repertório, a arte ajuda na organização do ser. Nunca saberemos quando o que oferecemos será acessado. Daí a importância de sempre nutrir a alma com arte (M. 5, Relato via WhatsApp, junho de 2020).
\end{abstract}

As mães compreendem o desenvolver dos conhecimentos e as habilidades nas crianças, ressaltam afetivamente que a exploração da casa e suas diversas formas de experimentação contribui com o bem viver de seus filhos, parecem entender que é "na relação com a liberdade, a alegria, o afeto e a parceria dos adultos, aspectos fundamentais para o sucesso das aprendizagens" (CHANAN, 2016, p. 17), que seus bebês podem crescer com mais alegria. É como a mãe M. 1 relata:

A arte é importante em todo nosso processo educativo, do caráter, inclusive. A arte exige bastante disciplina, então as pessoas acabam se organizando um pouco. Desde criança eu gosto de arte, [..] e eu quero isso para meus filhos, o quanto antes na vida deles, de serem inseridos nas artes. Que eles tenham mais oportunidades, das experiências que eles quiserem, de várias experiências. (M. 1, mensagem de áudio por whatsapp, julho de 2020).

Do mesmo modo, concordamos que é nessa transformação e (re) construção na relação com as mães através da experimentação dos bebês no cotidiano de suas casas, que, para essas mulheres, o ambiente também refloresce em outros significa- 
dos e ganha novos movimentos e empreendimentos estéticos, sonoros e performáticos em casa, antes esquecidos com o amadurecimento e os afazeres limitantes na vida adulta.

\section{CONSIDERAÇÕES}

De modo planejado ou não, no cotidiano doméstico limitado e atarefado que o isolamento social impõe às mães, parece que a sujeita brincante dessas adultas foi acionada na relação com seus/suas bebês, do mesmo modo que nessa relação (re) construída no presente, ambos parecem permitir experimentar e (re)produzir o que concebem ou vão entender um dia como arte, nos tempos e espaços disponíveis em seus lares. Isso nos leva a enfatizar que os adultos necessitam de um exercício a ser desenvolvido: o de (re)orientar os sentidos para entender como as artes são vividas e produzidas na primeira infância, isto é, temos que desmontar nosso olhar adultocêntrico ao entender que as crianças, em suas alteridades, (re)conhecem e (re)produzem no mundo as artes de modo relacional e sensível com as pessoas e coisas.

Neste estudo, percebemos que é no que já se dispõe em casa que as crianças pequenas mais entram em contanto com as artes, isso se revelou nas rotinas domésticas com suas mães e nas práticas inseridas nesses cotidianos para alegrar, educar e aprender junto. A vivência com/dos bebês no acesso às linguagens artísticas, mesmo que dependente da percepção e do conhecimento de suas/seus cuidadoras e os tempos entre seus trabalhos domésticos, home office, dos recursos materiais disponíveis em casa, são nos espaços que os bebês podem ocupar e explorar em seus lares que as artes se (re) fazem.

Na percepção de como os adultos e seus irmãos com mais idade interagem com as coisas e no que descobrem e imaginam ao experimentá-las em distintos contextos, os bebês aprendem, improvisam e (re) criam sensivelmente, se fazendo perceber pelos adultos à sua volta, bem como transformam o ambiente de casa a partir do agenciamento de suas experiências no ato de sentir o mundo. 
Porém, problematizamos que as referências e possibilidades artísticas também se mostram limitadas de acordo com as condições sociais que as famílias vivem. Apesar do esforço das mães ao conectarem as artes em seus lares, como modos prazerosos de experimentar o ambiente por parte dos bebês, parece que suas intenções esbarram no acesso à essas linguagens também em seus cotidianos de modo proveitoso. $O$ tempo dividido entre seus afazeres e compromissos de trabalho, reflete em como os bebês também aprendem e experienciam o espaço-tempo de suas casas.

Reconhecendo que é no/com o próprio corpo que os bebês sentem a arte de viver em sociedade, é numa mistura de afetos, descontentamentos e desafios que eles descobrem como movimentar o cotidiano em (re) criações. Do mesmo modo, ao refletirmos a arte para bebês, arte dos bebês ou a arte com os bebês em casa, compreendemos que os lares representados nessa pesquisa, são universos que dão sentidos artísticos para os bebês, mesmo que de modo não intencional pelas mães e outros cuidadores, afirmamos que seus desejos e seus empenhos se mostram criativos, ao explorarem os seres viventes e ao darem vida aos seres estáticos.

\section{REFERÊNCIAS}

ABRAMOWICZ, Anete; LEVCOVITZ, Diana; RODRIGUES, Tatiane Cosentino. Infâncias em Educação Infantil. Revista ProPosições. Vol. 20, n. 3 p. 179-197, Campinas Sept./Dec. 2009. Disponível em: https://www.scielo.br/scielo.php?pid=S0103$73072009000300012 \&$ script=sci_arttext.

Acesso em: 15 ago. 2020.

ALANEN, L. Explorations in generational analysis. In: ALANEN; MAYALL. Conceptualizing Child-Adult Relations. London, New York: Routledge/Falmer, 2001. p. 11-23.

CHANAN, Marcela. Exploração, Brincadeira e Arte: bebês em ação. Educação Infantil. Revista Direcional Educador. Edição 
no 132, p. 14-17, dez. 2016. Disponível em: http://sitecommerce. com.br/pana/wp-content/uploads/2018/04/post-educ-3.pdf Acesso em: 20 jun. 2020.

CUNHA, Sandra Mara da. Crianças fazendo arte: processos de criação artística e formação profissional docente para a Educação Infantil. P O I É S I S - Revista do Programa de Pósgraduação em Educação - Mestrado - Universidade do Sul de Santa Catarina. Unisul, Tubarão, v. 12, n. 21, p. 235-250, Jan/Jun 2018. Disponível em: 8. http://www.portaldeperiodicos.unisul. br/index.php/Poiesis/index. Acesso em: 29 jun. 2020.

GOTTLIEB, Alma. Para onde foram os bebês? Em busca de uma antropologia de bebês (e de seus cuidadores). Psicologia USP. São Paulo, julho/setembro, 2009, 20(3). p. 313-336. Disponível em: https://www.scielo.br/scielo.php?script=sci arttext\&pid=S0103-65642009000300002.

Acesso em: 20 jun. 2020.

INFANTINO, Agnese; ZUCCOLI, Franca. A arte como ferramenta de exploração e conhecimento. Revista Eventos Pedagógicos. Educação de 0 a 3 anos em espaços de vida coletiva. v. 6, n. 3 (16. ed.), edição especial temática, p. 75-94, ago./out. 2015.

INGOLD, Tim. Trazendo as coisas de volta à vida: Emaranhados criativos num mundo de materiais. Horizontes Antropológicos. Porto Alegre, ano 18, n. 37, p. 25-44, jan./jun. 2012.

KAISER, Patrícia Nunes De. Arte na educação infantil: o desenvolvimento infantil e a criança produtora de cultura. Dissertação (Mestrado em Educação) Faculdade de Educação da Universidade de Brasília. Brasília/DF, 2017.

LAHIRE, Bernard. Sucesso escolar nos meios populares: as razões do improvável. São Paulo: Ática, 1997.

LATOUR, B. Reassembling the social: an introduction to actor- 
network-theory. New York: Oxford University Press, 2005.

LÓPEZ, María Emilia. A arte na primeira infância. O valor das experiências à pouca idade. In: Cultura e Primeira Infância. Centro Regional para o Fomento do Livro na América Latina e no Caribe. p. 23-25. UNESCO, jun. 2013.

NAÇÕES UNIDAS BRASIL. OMS divulga recomendações sobre uso de aparelhos eletrônicos por crianças de até 5 anos. Disponível em: https://nacoesunidas.org/oms-divulgarecomendacoes-sobre-uso-de-aparelhos-eletronicos-porcriancas-de-ate-5-anos/. Acesso em: 20 jul. 2020.

NUNES, Laísy de Lima; AQUINO, Fabíola de Sousa Braz; VILLACHAN-LYRA, Pompéia. Mãe Acha que Bebê Sente Tudo, né?: Concepções Maternas sobre Habilidades Socioemocionais e Comunicativas Infantis. Revista Psico. Porto Alegre, v. 46, n. 2, p. 243-253, abr.-jun. 2015. Disponível em: http://revistaseletronicas. pucrs.br/ojs/index.php/revistapsico. Acesso em: 15 jul. 2020.

OLIVEIRA, Andréa. Educação Infantil: o conhecimento das artes visuais. Cursos CP. Cursos Educação Infantil. Artigos. Disponível em https://www.cpt.com.br/cursos-educacao-infantil/artigos/ educacao-infantil-o-conhecimento-das-artes-visuais. Acesso em: 01 jun. 2020.

OLIVEIRA, Marcia Franco De. Representações sociais e concepções dos professores sobre arte na infância e implicações na educação infantil. Dissertação (Mestrado em Artes e Educação) Universidade Estadual Paulista. UNESP. São Paulo, 2016.

PAASCHEN, Liane Elisabeth Driemeyer. Corpo e Sentidos: uma possibilidade de ensino da arte para bebês. XIII Seminário Internacional de Educação. Escola Espaço de Sociabilidade e Cultura da Paz. 2012. Disponível em: http://www.feevale.br/site/ hotsite/tpl/153/comum/arquivos/pratica_docente/corpo\%20 
e\%20sentidos $\% 20-\% 20$ uma\%20possibilidade $\% 20$ de $\% 20$ ensino\%20da\%20arte\%20para\%20beb\%c3\%8as.pdf acesso em: 20 jun. 2020.

PIRES, Flávia Ferreira; SARAIVA, Marina Rebeca. In: Dossiê: A antropologia dos bebês e suas cuidadoras. Áltera: revista de Antropologia. PPGA - Programa de Pós-Graduação em Antropologia da UFPB- Universidade Federal da Paraíba. João Pessoa, v. 1, n. 8, jan./jun. 2019. Disponível em: http://periodicos. ufpb.br/ojs2/index.php/altera. Acesso em: 10 jun. 2020.

SALUTTO, Nazareth; NASCIMENTO, Anelise Monteiro do. Onde estão os bebês? Reflexões para sua construção conceitual a partir de um debate interdisciplinar. In: Dossiê: A antropologia dos bebês e suas cuidadoras. Áltera: revista de Antropologia. PPGA - Programa de Pós-Graduação em Antropologia da UFPBUniversidade Federal da Paraíba. João Pessoa, v. 1, n. 8, jan./jun. 2019. Disponível em: http://periodicos.ufpb.br/ojs2/index.php/ altera. Acesso em: 24 jul. 2020.

TOREN, Christina. Antropologia e psicologia. Revista brasileira de ciências sociais, Caxambu, vol. 27, nº 80, 2012.

TEBET, Gabriela de Campos; ABRAMOWICZ, Anete. Estudos de bebês: linhas e perspectivas de um campo em construção. ETD - Educação Temática Digital. Campinas, SP. V. 20 n. 4, p. 924946, out./dez. 2018.

WINNICOTT, Donald Woods. Primeiras experiências de independência. In: WINNICOTT, D. A criança e seu mundo. Rio de Janeiro: Ed. LTC., 1982 [1964]. 6ª edição. p 189-195. 